\title{
Higienização e manutenção de prótese total fixa sobre implante
}

\author{
Hygienization and maintenance of implant-supported fixed prosthesis \\ Higienización y mantenimiento de prótesis fija sobre implantes \\ Eduardo Marques de LIVIO$^{1}$ \\ Rafael dos Santos SILVA ${ }^{2}$ \\ Rodrigo Lorenzi POLUHA ${ }^{3}$ \\ ${ }^{1}$ Cirurgião-Dentista, Universidade Estadual de Maringá (UEM) 87020-900 Maringá-PR, Brasil
}

${ }^{2}$ Professor Adjunto do Departamento de Odontologia da Universidade Estadual de Maringá (UEM) 87020-900 Maringá-PR, Brasil

${ }^{3}$ Doutorando,Programa de Pós-Graduação em Reabilitação Oral, Faculdade de Odontologia de Bauru da Universidade de São Paulo FOB/USP 17012-901 Bauru-SP, Brasil

\section{Resumo}

As próteses fixas sobre implante são consideradas a primeira opção para a reabilitação de pacientes com perdas dentárias. A higienização e a manutenção dessas próteses são de suma importância para a longevidade da reabilitação. O objetivo desse estudo foi revisar a literatura a respeito dos diferentes materiais para higienização e manutenção de prótese total fixa sobre implante. Os principais materiais usados na higienização são: escovas dentais; escovas interdentais; fio dental; irrigador oral; creme dental; e, enxaguatórios bucais. A literatura demonstra que o controle de placa é de estrema importância para a longevidade das próteses e esse controle é obtido através de uma boa instrução de higiene oral proveniente do dentista, orientando o paciente sobre os diversos dispositivos possíveis de serem utilizados, juntamente com consultas de manutenção em períodos adequados.

Descritores: Higiene Bucal; Implantes Dentários; Manutenção.

\begin{abstract}
Implant-supported fixed prostheses are considered the first option for the rehabilitation of patients with tooth loss. The hygiene and maintenance of these prostheses are very important for the longevity of the rehabilitation. The objective of this study was to review the literature regarding the different materials for hygiene and maintaining for implant-supported fixed prostheses. The main materials used in the hygiene are toothbrushes; interdental brushes; floss; oral irrigator; toothpaste; and mouthwashes. The literature demonstrates that plaque control is of paramount importance for the longevity of prostheses and that this control is obtained through a good oral hygiene instruction from the dentist, guiding the patient about the various possible devices to be used, together with maintenance appointments at the appropriate times.
\end{abstract}

Descriptors: Oral Hygiene; Dental Implants; Maintenance.

\section{Resumen}

Las prótesis fijas con soporte de implantes se consideran la primera opción para la rehabilitación de pacientes con pérdida de dientes. La higiene y el mantenimiento de estas prótesis son muy importantes para la longevidad de la rehabilitación. El objetivo de este estudio fue revisar la literatura sobre los diferentes materiales para la higiene y el mantenimiento de prótesis fijas con soporte de implantes. Los principales materiales utilizados en la higiene son cepillos de dientes; cepillos interdentales; seda floja; irrigador oral; pasta dental; y enjuagues bucales. La literatura demuestra que el control de la placa es de suma importancia para la longevidad de las prótesis y que este control se obtiene a través de una buena instrucción de higiene bucal del dentista, que guía al paciente sobre los diversos dispositivos posibles que se deben utilizar, junto con las consultas de mantenimiento en los lugares apropiados.

Descriptores: Higiene Bucal; Implantes Dentales; Mantenimiento.

\section{INTRODUÇÃO}

Próteses dentárias implanto-suportadas tem sido a primeira opção para a reabilitação protética de pacientes total ou parcialmente desdentados, em virtude de proporcionarem uma reabilitação funcional, estética e fonética com alta retenção, estabilidade, conforto e mínima reabsorção óssea ${ }^{1}$. As principais modalidades para a reabilitação implanto-suportada de arcos edêntulos são as overdenture e as próteses totais fixas (protocolo de branemark), sendo que ambas possuem benefícios e limitações ${ }^{1,2}$.

Diversos fatores contribuem para o sucesso do tratamento reabilitador implanto-suportado, como a distância dada entre os implantes e angulação dos mesmos no momento da cirurgia; o perfil de emergência da prótese, sendo ele convexo, o que favorece a higienização e é esteticamente agradável; o material utilizado na base de protocolos, estudos apontam as bases em resina composta levam a um maior acúmulo de placa e inflamação gengival; e por último e de fundamental importância a higienização e manutenção feita pelo paciente ${ }^{2,3}$.

A literatura considera um dos principais responsáveis pelo insucesso dos implantes os quadros de peri-implantes não tratados ou instalados por falta de instrução sobre higiene oral ${ }^{3}$. A higienização oral e eliminação da placa bacteriana é essencial para a longevidade de implantes osseointegráveis ${ }^{4}$. A remoção do acúmulo microbiano inicial nas superfícies dos implantes dentários, aliada à eliminação de pelo menos $85 \%$ do biofilme de placa bacteriana das peças próteticas pelo paciente é crucial para o sucesso em longo prazo da longevidade do tratamento reabilitador ${ }^{5}$.

O cirurgião-dentista é fundamental na instrução e motivação da correta higienização feita pelo paciente. Conforme apresentado na literatura ${ }^{4}$ os principais materiais usados na higienização são: escovas dentais, escovas interdentais, fio dental, irrigador oral, creme dental e enxaguatórios bucais. Uma revisão aprofundada sobre os materiais para higienização na reabilitação implanto-suportada pode contribuir na formação e prática do clínico, bem como beneficiar a saúde dos pacientes. Baseado nisso, o estudo objetiva revisar a literatura a respeito dos diferentes materiais para higienização e manutenção de prótese total fixa sobre implante.

\section{MATERIAL E MÉTODO}

Foi realizada uma busca eletrônica, não sistemática, nas bases de dados Lilacs, Pubmed/Medline, Scielo e ScienceDirect, cruzando-se os seguintes descritores 
em língua inglesa e portuguesa: "Oral Hygiene"; "Dental Implantation", "Maintenance" Foram incluídos artigos de revisão de literatura, revisão sistemática, meta-análise, estudos clínicos randomizados, além de livros pertinentes ao assunto, publicados no período de 1995 a 2018.

\section{RESULTADOS}

\section{- Escovas Dentais}

Inúmeros tipos de escovas dentais são utilizadas para a higienização das reabilitações orais. As com cerdas macias são mais efetivas para acessar regiões sulculares o que a torna um dispositivo bastante interessante para a remoção de placa bacteriana do pilar acima do implante, além de alcançar as regiões vestibulares e linguais da prótese. Algumas angulações da escova e modos como executar os movimentos são indicados pelo dentista de acordo com apropriado para o paciente. A técnica de Bass é eficiente por manter limpa as superfícies das próteses e obter uma boa saúde das estruturas de suporte $^{5}$. O grande benefício desta técnica é a fácil execução, facilitando os movimentos de higienização. As cerdas da escova devem ficar colocadas na área do sulco gengival e peri-implantar a um ângulo de 45 graus ${ }^{6}$.

A indicação de escovas elétricas ainda apresente controvérsia. Costa et al. $^{7}$ e Vandekerckhove et al. ${ }^{8}$ em seus estudos apontam uma maior efetividade na qualidade de higienização quando as escovas elétricas são comparadas com as escovas manuais ${ }^{7,8}$. Esses resultados são colaborados por Wolff et al. ${ }^{9}$ que concluiu em seu estudo que pacientes que realizaram higienização com escovas elétricas tiveram o índice de placa e a inflamação gengival reduzidos. No contraponto, Tawse-Smith et al. ${ }^{10}$ mostraram que não há diferença entre o uso de escovas elétricas e escovas manuais, sendo a qualidade da higienização mais dependente da técnica e habilidade do paciente do que da escova utilizada $^{10}$. Além disso, pode haver uma relação entre o uso de escovas elétricas e recessões gengivais ${ }^{11}$ ou abrasão gengival, pelo uso incorreto dos dispositivos ${ }^{12}$.

\section{- Escovas Interdentais}

São pequenas escovas que possuem diâmetros variáveis, com filamentos de nylon finos e longos, planejados para preencher espaços vazios como as áreas críticas entre pônticos e tecido de suporte, realizando assim uma limpeza suave eficaz. São indicadas na maioria das vezes para pacientes com dificuldade no uso de fio dental. Para evitar pequenos desgastes nas estruturas de acrílico elas são elaboradas com a porção central revestida de plástico ou nylon ${ }^{6}$.

\section{- Fio Dental}

Utilizados para a higienização entre implantes, o fio dental com passa fio ou o superfloss são boas indicações. O modo indicado de uso é a inserção do fio de vestibular para a lingual do implante, retornando-o pela vestibular, formando um "U". É indicado também que use o fio dental embebido em uma solução de Clorexidina 0,12\%, carregando-o até o sulco gengival para uma inibição de formação de placa bacteriana ${ }^{13}$.

- Irrigador Oral

São aparelhos eficazes na higienização sua forma de limpeza é por meio da irrigação. O WaterPik® (Teledyne Water Pik, CO, EUA) é o mais conhecido e utilizado, auxiliando na eliminação e remoção de detritos e resíduos alimentares. $\mathrm{O}$ uso de irrigação artificial é um benéfico meio de remoção de placa supragengival ao redor do implante. Contudo, deve-se ter precauções em sua utilização, o incorreto uso e excessiva pressão da água pode danificar o epitélio juncional e permitir uma disseminação de bactérias sugerindo-se que seja utilizada com baixa pressão ${ }^{14}$.

\section{- Creme Dental/Enxaguatórios}

Cremes dentais com potencial ácido (fluoretos ácidos) e com materiais abrasivos não devem ser utilizados por causarem corrosão e desgastes da superfície do implante. Pastas de dentes contendo fluoreto estanoso (Crest Pro-Health - Oral B) ou Triclosan (Colgate Total, NY, EUA) proporcionam benefício antiplaca e antigengivite; além disto, o fluoreto de estanho pode proteger contra sensibilidade que é mais comum entre os pacientes com doença periodontal ${ }^{5}$.

Dentre os enxaguatórios o Digluconato de Clorexidina (DC), é um dos agentes antimicrobianos mais potentes sendo altamente eficaz e utilizada como padrão ouro em relação à potência de outros agentes. O DC receitado na forma de $0,2 \%$ ou $0,12 \%$ sendo líquido, gel ou spray. Suas principais indicações são para período pós-operatório e para higienização de próteses, duas vezes ao dia. Para pacientes submetidos a cirurgias com implantes, Francetti et al $(2004)^{15}$ realizou uma pesquisa comparando o uso de bochechos $(15 \mathrm{ml}$ de Clorexidina $0,12 \%)$ e spray $(0,2 \%$ de Clorexidina) aplicado no sítio do implante. Ambos os grupos obtiveram um resultado satisfatório quando se trata de redução do índice de placa bacteriana. A sugestão do spray ocorre devido a possibilidade de focalizar a pulverização, sendo o tratamento específico para cada região, isto reduz o uso total de drogas utilizadas. Outro fator positivo reflete na menor coloração das interproximais de dentes quando utilizado a forma em spray. O uso deve ser feito sempre com cautela pois pode causar manchamento dos materiais do implante além de poder alterar o paladar do paciente ${ }^{15}$.

- Manutenção Clínica

O exame clínico deve avaliar o aspecto da mucosa (inflamação, consistência, volume e contorno), o controle de índice de placa e cálculo gengival. A ausência de sangramento á sondagem é 
um fator admirável de saúde peri-implantar. Os tecidos intraorais devem ser palpados a fim de se detectar edema, sensibilidade, exsudato ou supuração $0^{4,16}$. A literatura expõe valores de sondagem para os tecidos "saudáveis" ao redor de implantes na faixa de $3 \mathrm{~mm}$ aproximadamente nas diferentes faces. Entretanto, não se é possível ainda afirmar se o sangramento presente durante a sondagem periodontal em implantes osseointegráveis é sinal de doença ou saúde periimplantar ${ }^{16}$. Todavia a presença de bolsas profundas durante a sondagem ao redor dos mesmos denuncia altos níveis de microrganismos. É papel do cirurgião dentista a remoção de cálculos para obter novamente saúde peri-implantar, a utilização de ultrassom e curetas de titânio podem causar danos na superfície dos implantes, é aconselhável a utilização de curetas de plástico e taças de borracha para fazer a higienização ${ }^{5}$.

O acompanhamento clínico é importante para o sucesso longitudinal do tratamento. Muitos autores afirmam ser necessário visitas rotineiras ao dentista durante o primeiro ano (referências desses muitos autores). No primeiro mês, após a instalação da prótese implanto-suportada; aos três meses; e se o paciente não apresentar doenças peri-implantares as visitas passam a ser semestrais; exames radiográficos periapicais são indicados em todas as consultas para verificar a estabilidade do implante, assim como a motivação e a instrução de uso dos dispositivos da auto-higienização ${ }^{16}$.

\section{DISCUSSÃO}

Após a realização de criterioso exame clínico, e uma detalhada anamnese, o dentista deve se ater ao perfil do paciente e os motivos que o levaram às perdas dentárias para que possa certificar se o tipo de prótese proposta está bem indicado. A eficiência do programa de manutenção oral regular em prótese implanto-suportada pode se utilizar de diferentes métodos e dispositivos para a higienização bucal, entretanto deve-se oferecer ao paciente uma cuidadosa orientação por escrito, um tempo clínico para motivação e explicação da importância e técnicas dos diferentes dispositivos ${ }^{4}$.

Um número maior de consultas no primeiro ano após a instalação da prótese sobre implante é aconselhável. Durante as visitas ao dentista a remoção de cálculos, na base da prótese e em torno do implante é necessária, recomenda-se o uso de curetas plásticas e, polimentos com taças de borracha, alguns autores não aconselham o uso de ultrassom e de curetas de titânio pois podem causar dano na superfície do implante o que possivelmente se torna um foco de acúmulo de placa bacteriana ${ }^{5}$.

Escovas dentais macias com pastas sem abrasivos são o primeiro passo para a higienização da prótese, a técnica de Bass é mais aconselhável. Para pacientes com dificuldade motora escovas elétricas são indicadas a fim de obter um resultado mais satisfatório $^{5,6}$.

A utilização de hidropropulssores, fio dental com passa fio ou superfloss, são importantes para auxiliar na emoção de biofilme. A Clorexidina $0,12 \%$ ou $0,2 \%$ não apresenta uma diferença estatística quanto ao auxílio no controle de placa, mas pode ser prescrita para auxiliar na higienização em curtos períodos de tempo, no pós-operatório ou em áreas com inflamação, sempre tomando cuidado com os efeitos colaterais que esta pode provocar ${ }^{6}$.

Uma rotina de cuidados deve ser estabelecida e mantida para monitorar a boa estabilidade dos implantes dentários. Instruções de higiene oral devem ser aplicadas em todas as visitas. Agendamento de visitas mensais deve ser feita após a instalação do implante, nestas o dentista deve analisar a saúde periimplantar e o auto-cuidado do paciente reforçando as práticas de higienização ${ }^{16}$.

\section{CONCLUSÃO}

O estudo e o conhecimento sobre as técnicas para higienização e manutenção de próteses totais fixas sobre implante são fundamentais para o sucesso do tratamento clínico. É necessário tempo clínico para motivar o paciente à auto-higienização alertando-o que esta é imprescindível para longevidade da prótese.

\section{REFERÊNCIAS}

1. Corbella S, Del Fabbro M, Taschieri S, De Siena F, Francetti L. Clinical evaluation of an implant maintenance protocol for the prevention of periimplant diseases in patients treated with immediately loaded full-arch rehabilitations. Int $\mathbf{J}$ Dent Hyg. 2011;9(3):216-22.

2. Drago C, Howell K. Concepts for designing and fabricating metal implant frameworks for hybrid implant prostheses. J Prosthodont. 2012; 21(5):413-24.

3. Braceras I, Ipinazar E, Maeztu MA, Alava JI. Risk analysis and implants. Med Eng Phys. 2008; 30(9):1201-204.

4. Kebir M, Davarpanah M, Mattout P, Mattout C. Manutenção em Implantodontia. In: Darvapanah M. Manual de implantodontia clínica. Porto Alegre: Armed; 2007. p. 258-65.

5. Kracher CM, Smith WS. Oral health maintenance dental implants. Dent Assist. 2010;79(2):27-35.

6. Sison SG. Implant maintenance and the dental hygienist. Acess Special Supplement. 2003:1-13.

7. Costa MR, Marcantonio RA, Cirelli JA. Comparison of manual versus sonic and ultrasonic toothbrushes: a review. Int J Dent Hyg. 2007; 5(2):75-81

8. Vandekerckhove B, Quirynen M, Warren PR, Strate J, van Steenberghe D. The safety and efficacy of a powered toothbrush on soft tissues in patients with implant-supported fixed prostheses. 
Clin Oral Investig. 2004;8(4):206-10

9. Wolff L, Kim A, Nunn M, Bakdash B, Hinrichs J. Effectiveness of a sonic toothbrush in maintenance of dental implants a prospective study. J Clin Periodontol. 1998;25(10):821-28.

10.Tawse-Smith A, Duncan WJ, Payne AG, Thomson WM, Wennström JL. Relative effectiveness of powered and manual toothbrushes in elderly patients with implant-supported mandibular overdentures. J Clin Periodontol. 2002;29(4):275-80.

11.Johnson BD, McInnes C. Clinical evaluation of the efficacy and safety of a new sonic toothbrush. J Periodontol. 1994;65(7):692-97.

12. Tritten CB, Armitage GC. Comparison of a sonic and a manual toothbrush for efficacy in supragingival plaque removal and reduction of gingivitis. J Clin Periodontol. 1996;23(7): 641-48.

13.Carranza JR, Newman MG. Periodontia clínica. 8 ed. Rio de Janeiro: Guanabara Koogan; 1997.

14.Brough Muzzin KM, Johnson R, Carr P, Daffron $\mathrm{P}$. The dental hygienists role in the maintenance of osseointegrated dental implants. J Dent Hyg. 1988;62(9):448-53.

15.Francetti L, Del Fabbro M, Basso M, Testori T, Taschieri S, Weinstein R. Chlorhexidine spray versus mouthwash in the control of dental plaque after implant surgery. J Clin Periodontol. 2004; 31(10):857-62.

16. Roccuzzo M, Layton D, Roccuzo A, HeitzMayfield L. Clinical outcomes of per-implantitis treatment and supportive care: a systematic review. Clin Oral Impl Res. 2018;29(3):31-5.

\section{CONFLITO DE INTERESSES}

Os autores declaram não haver conflitos de interesse.

\section{AUTOR PARA CORRESPONDENCIA}

\section{Rodrigo Lorenzi Poluha}

rodrigopoluha@gmail.com

Submetido em 01/04/2019

Aceito em 01/05/2019 